\title{
AVALIAÇÃO MICROBIOLÓGICA DE DESINFETANTES QUÍMICOS DE USO DOMÉSTICO
}

\author{
Jorge Timenetsky*
}

\begin{abstract}
TIMENETSKY, J. Avaliação microbiológica de desinfetantes químicos de uso doméstico. Rev. Saúde públ. S. Paulo, 24: 47 - 50, 1990 .
\end{abstract}

RESUMO: Em 1988 e no primeiro semestre de 1989 cinco desinfetantes de uso doméstico foram divulgados através de publicaçăo televisiva. Para avaliar as propriedades antimicrobianas desses produtos os mesmos foram testados por um método qualitativo (Diluição-Uso com 10 carreadores, método convencional e outro simplificado adaptado) e outro quantitativo, também adaptado. Os compostos ativos dos produtos descritos nos respectivos rótulos foram: 1 - Paraclorofenol (O- Benzil) $0,1 \% ; 2$ - Eter 2,4,4' Cloro (III) $2^{\prime}$ hidroxifenilico $0,1 \% ; 3-\mathrm{N}$-alquildimetil benzil amônio-Cloreto de alquil dimetil etil benzil amônio $50 \%$ - 1,6\%; 4 - formaldeído $37 \%$ (solução de $0,3 \%$ ); 5 - Sem informação. Os microrganismos utilizados foram: Staphylococcus aureus ATCC 6538, Pseudomonas aeruginosa ATCC 15442 e Salmonella choleraesuis ATCC 10708. No método qualitativo, a cepa de pseudomonas foi recuperada dos desinfetantes 1,2 e 3 . Todos os desinfetantes mostraram um efeito germicida de 5,0 $(99,999 \%$ de redução) em 15 segundos frente às três cepas. O desinfetante 3 estava contaminado com Enterobacter sp na ordem de $10^{4}$ células por ml. Este contaminante foi sensível diante dos desinfetantes 1,4 e 5, frente à metodologia qualitativa, e relativamente resistente frente ao desinfetante 2, na metodologia quantitativa.

DESCRITORES: Desinfetantes. Avaliação microbiológica.

\section{INTRODUÇÃO}

Em 1985, no Brasil, adotou-se a diluição-uso, padronizada pela Association of Official Analytical Chemist (AOAC), como método oficial na avaliação microbiológica de desinfetantes, para qualificar esses produtos para efeito de registro e comercialização ${ }^{4,6}$.

Muitos desinfetantes de uso hospitalar, na ocasião, foram desqualificados por não atingirem os padrões microbiológicos necessários ${ }^{7}$. Desde então, os fabricantes começaram a alterar a formulação e a embalagem de seus produtos desinfetantes, bem como a melhorar o esclarecimento para seu uso, atendendo às novas exigências ${ }^{8}$. Numa etapa intermediária deste programa, alguns produtos, com a formulação já alterada, apesar de qualificados microbiologicamente, foram considerados tóxicos ${ }^{8,9}$.

Desta maneira, diante da necessidade de qualificar maior número de produtos, procurou-se conciliar a baixa toxicidade com o espectro de ação antimicrobiano na desinfecção hospitalar. Assim, flexibilizaram-se alguns padrões microbiologi$\cos ^{8,9}$ sem o comprometimento da qualidade do produto. Essa avaliação não foí divulgada e discutida para produtos desinfetantes de uso doméstico em sua grande variedade, como ocorreu com os desinfetantes hospitalares, por razões diversas. Novos desinfetantes domésticos estão surgindo e coexistindo com outros mais antigos ou tradicionais ${ }^{15}$. É sabido que os desinfetantes domésticos, por questões inerentes à sua comercialização, são escolhidos pelo consumidor com base em critérios arbitrários e/ou subjetivos e, conseqüentemente, empregados erroneamente. Embora esses produtos não possuam os mesmos objetivos que os de uso hospitalar, devem, do mesmo modo, possuir atividade antimicrobiana por definição e atender aos respectivos padrões microbiológicos que por sua vez são mais flexíveis do que os de uso hospitalar 1,4,14,15 (domésticos - avaliados com 2 espécies bacterianas; hospitalares avaliados com 5 espécies bacterianas e uma fúngica, conforme o ambiente hospitalar).

A metodologia da diluição-uso pode qualificar ou desqualificar um mesmo produto desinfetante, dependendo do laboratório que realiza a trabalhosa metodologia padronizada. Desta maneira, sugere-se que poucos laboratórios sejam credenciados para avaliação e que a metodologia seja simplificada ${ }^{10}$.

Assim, no sentido de colaborar com o estudo da avaliação microbiológica de desinfetantes de uso doméstico, área carente em nosso meio ${ }^{3,15}$, propusemo-nos a realizar estudo com 5 produtos desinfetantes divulgados pela publicidade televisiva, no ano de 1988, e no primeiro semestre de 1989, por metodologia quantitativa adaptada e outra qualitativa, esta baseada na metodologia da diluição-uso utilizando etapas padronizadas e outras simplificadas.

* Departamento de Microbiologia do Instituto de Ciências Biomédicas da Universidade de São Paulo - Av. Prof. Lineu Prestes, 1.374 — 05508 — São Paulo, SP - Brasil. 


\section{MATERIAL E METODOS}

Microorganismos ${ }^{8}$ :

Staphylococcus aureus ATCC 6538

Pseudomonas aeruginosa ATCC 15442 e

Salmonella choleraesuis ATCC 10708

\section{Desinfetantes:}

(composto ativo e concentração descrita no rótulo).

1 - Pinho-sol (Ortobenzil paraclorofenol a 0,1\%)

2 - Frish (Éter 2,4,4' tricloro 2' hidroxifenílico a $0,1 \%$ )

3 - Harpic-WC (Cloreto de alquil dimetil benzil amino-cloreto de alquil dimetil etil benzil amino 50 a $1,6 \%$ )

\section{4 - Pato-Purific (Formaldeído $37 \%$, sol a $0,3 \%$ )}

\section{5 -Thunder - (Não apresenta formulação)}

\section{Meios de subcultivo ${ }^{4}$ - Caldo e Agar Nutriente}

Método qualitativo: Diluição-uso padronizada pela $A O A C^{4}$ com 10 carreadores, para efeito de triagem, inoculados separadamente nos respectivos subcultivos. Diluição-uso método simplificado adaptado neste trabalho, baseado nos mesmos princípios da $\mathrm{AOAC}^{4}$, com 10 carreadores para efeito de triagem, inoculados conjuntamente em frascos Erlernmeyer com $100 \mathrm{ml}$ de meio para subcultivo.

Método quantitativo adaptado ${ }^{15}$ - Determinação do efeito germicida. Suspensão teste $(0,5 \mathrm{ml}$ de caldo nutriente com bactérias desenvolvidas em $24 \mathrm{~h}+5,0 \mathrm{ml}$ do desinfetante em teste). Verificação do número de unidades formadoras de colonnias (u.f.c.) sobreviventes após 15 segundos de contato.

A suspensão teste foi avaliada pela amostra realizada com alça bacteriológica padronizada (4mm de diâmetro) 4 .

Confirmação da identidade das bactérias utilizadas no início de cada experimento quando os subcultivos foram positivos ${ }^{15}$.

Controle da interferència de resíduos de desinfetantes nos subcultivos na:

- Metodologia qualitativa padronizada: Carreadores estéreis foram mergulhados nas soluções dos desinfetantes, retirados, o excesso de desinfetante removido, e inoculados simultaneamente com carreadores contaminados para subcultivo a $37^{\circ} \mathrm{C}$ por $24 \mathrm{~h}^{15}$.

- Metodologia qualitativa simplificada: Carreadores estéreis foram mergulhados nas soluçōes desinfetantes, removidos em grupo de 10 e submetidos a lavagens cuidadosas com água destilada estéril, num Erlenmeyer (este procedimento também ocorreu na avaliação de cada produto); em seguida, foram inoculados e subcultivados conjuntamente com 10 carreadores contaminados em $100 \mathrm{ml}$ de Caldo Nutriente.

- Metodologia quantitativa adaptada: Inoculouse simultaneamente em $15 \mathrm{ml}$ de Agar Nutriente, fundido e resfriado, uma alçada da solução do desinfetante e outra de uma suspensão conhecida de bactérias para a verificação da alteração de u.f.c., após incubação a $37^{\circ} \mathrm{C}$ por $24 h^{15}$.

\section{RESULTADOS E DISCUSSÃO}

Como já constatamos em outra oportunidade, a metodologia da diluição-uso pode ocultar atividade antimicrobiana importante. Portanto, um acompanhamento pela avaliação quantitativa é sempre interessante ${ }^{15}$.

Para colaborar com a recente proposta de simplificar o método de avaliação microbiológica de desinfetante e tendo por base a metodologia da diluição-uso, conferimos que o fato de 10 carreadores tratados com desinfetante e subcultivados conjuntamente não alterava os resultados em relação ao método padronizado para fins de triagem. Assim, a economia de tempo, material e, conseqüentemente, a atividade técnica pôde ser reduzida sem interferir nos princípios da metodologia (Tabela).

Diante da metodologia qualitativa, tanto no protocolo padronizado como no simplificado, os produtos 2 e 3 permitiram a recuperação das cepas de Pseudomonas e de Salmonella. Desta maneira, apenas os produtos 1,4 e 5 estariam de acordo com o padrão microbiológico de triagem necessário aos desinfetantes domésticos. Os produtos 4 e 5 também atingiram padrões microbiológicos para desinfetantes institucionais e hospitalares destinados a áreas não críticas, pois não permitiram a recuperação da cepa de Pseudomonaș (Tabela).

A metodologia quantitativa por nós anteriormente adaptada ${ }^{15}$ mostrou que todos os produtos provocaram um efeito germicida de pelo menos 5 $(99,999 \%$ de redução) em 15 segundos sobre as bactérias padrões utilizadas. Esse tipo de redução é reconhecido e sugerido, desde que o inóculo inicial possua cerca de $10^{9}$ bactérias por $\mathrm{ml}^{5}$. Como em nosso caso o objetivo era apenas avaliar atividade antimicrobiana, a suspensão teste possuía cerca de $10^{7}$ bactérias por ml; entretanto, essa situação é semelhante ao número de bactérias contidas em cada cilindro carreador ${ }^{12}$, embora num método as bactérias estejam em suspensão e, em outro, aderidas à supcrfície metálica. A atividade antibacteriana evidenciada no método quantitativo não pode ser desprezada em relação ao método qualitativo, principalmente quando este é utilizado para a qualificação de produtos desinfetantes 4,13,10. 
TABELA

Método qualitativo (diluição-uso) padronizado (P) e simplificado (S) utilizado na avaliação microbiológica de produtos desinfetantes de uso doméstico

\begin{tabular}{lcccccc}
\hline Cepa padrão de & \multicolumn{2}{c}{ S. aureus } & \multicolumn{2}{c}{ P. aeruginosa } & \multicolumn{2}{c}{ S. choleraesuis } \\
\hline Método & P & S & P & S & P & S \\
\hline Desinfetante 1 & $0 / 10$ & - & $2 / 10$ & + & $0 / 10$ & - \\
Desinfetante 2 & $0 / 10$ & - & $1 / 10$ & + & $1 / 10$ & + \\
Desinfetante 3 & $0 / 10$ & - & $4 / 10$ & + & $3 / 10$ & + \\
Desinfetante 4 & $0 / 10$ & - & $0 / 10$ & - & $0 / 10$ & - \\
Desinfentante 5 & $0 / 10$ & - & $0 / 10$ & - & $0 / 10$ & - \\
Controle & $10 / 10$ & + & $10 / 10$ & + & $10 / 10$ & + \\
\hline
\end{tabular}

P- Número de tubos para subcultivo, num total de 10 , que permitiram a recuperação da cepa padrão.

S- Sobrevivência da cepa padrão a partir de 10 carreadores inoculados conjuntamente em $100 \mathrm{ml}$ de meio para subcultivo.

(-) Não houve recuperação da cepa padrão

(+) Houve recuperação da cepa padrão

Também é sabido que os testes "in vitro" conferem apenas a atividade antimicrobiana de um produto desinfetante mas não a real capacidade de desinfecção de um ambiente que, por sua vez, pode ter diversos fatores interferentes, alguns até imprevisíveis, prejuđicando a atividade antimicrobiana de um composto ativo ${ }^{13,15}$. Por esta razão, os testes padronizados ou não são discutíveis, e não existe um único método de avaliação microbiológica que considere todas as variáveis no contexto geral de desinfecção $0^{2,5}$. O uso de cepas bacterianas padrōes e representativas também é questionado pois, do mesmo modo, não representam as condiçōes reais num processo de desinfecção ${ }^{2,5}$.

$\mathrm{Na}$ avaliação quantitativa verificamos que o produto número 3 estava contaminado com Enterobacter $\mathrm{sp}$, na ordem de $10^{4}$ células por ml do produto. Esse produto, apesar de ter se revelado eficaz na metodologia qualitativa, padronizada e simplificada, frente à cepa de Staphylococcus, não o foi para a cepa de Salmonella, conferindo em nosso caso a representatividade de Salmonella choleraesuis. A atividade antibacteriana dos produtos $1,2,4$ e 5 foi realizada frente à cepa do microrganismo contaminante. Apenas o produto número 2 permitiu a recuperação de Enterobacter sp tanto na avaliação qualitativa quanto na quantitativa. Entretanto, na avaliação quantitativa, o produto número 2 revelou ainda possuir um efeito germicida de pelo menos 3 (99,9\% de redução) após $10 \mathrm{~min}$ de contato. Paradoxalmente, neste último experimento, a representatividade da cepa de Salmonella na metodologia qualitativa pode ser questionada.

$O$ achado da contaminação em questão, inclusive em outras embalagens do produto e pertecentes ao mesmo lote, pode sugerir descuidos na elaboração da formulação, estoque e/ou embala- gem do produto. Entretanto, é sabido que produtos desinfetantes à base de quaternários de amônio, caso do produto número 3 , são mais passíveis de contaminação por questões inerentes a esse composto, sendo, portanto, às vezes suplementados com preservantes como o etanol ${ }^{11}$. Sugerimos, portanto, que produtos desinfetantes de uso doméstico, à base de quaternários de amônio, sejam comercializados com cautela. $\mathrm{O}$ achado de cepas resistentes ou contaminantes faz parte do contexto geral do controle microbiológico de desinfetantes, com exceção das bactérias esporuladas $2,5,13$.

Os resíduos de desinfetantes levados para os subcultivos não interferiram no desenvolvimento bacteriano, nas metodologias quali e quantitativa.

Os subcultivos positivos confirmaram apenas a presença das cepas utilizadas no início de cada experimento, com exceção do produto número 3 onde também se caracterizou, através de isolamento, um microrganismo contaminante (Enterobacter $\mathrm{sp}$ ).

$\mathrm{Na}$ metodologia qualitativa com o produto 3 , todos os tubos para subcultivo apresentaram turvação; e apenas 4 tubos permitiram também a recuperação de Pseudomonas e 3 de Salmonella nos respectivos experimentos (Tabela). Na metodologia simplificada houve a recuperação da cepa bacteriana padrão juntamente com Enterobacter sp. $\mathrm{Na}$ metodologia quantitativa não houve a recuperaçăo das cepas padrões, apenas do microrganismo contaminante.

A alça bacteriológica padronizada transportou em média $5,3 \times 10^{5}$ células de Staphylococcus aureus, $8,7 \times 10^{5}$ células de $P_{\text {seudomonas aeruginosa e } 4,3}$ $\times 10^{5}$ células de Salmonella choleraesuis. 
Concluindo, os produtos desinfetantes divulgados através de um expressivo veículo de comunicação, a televisão, revelaram em nossas condições laboratoriais possuir atividade bactericida, atingindo um dos principais objetivos de um desinfetante. Entretanto, diante dos padrões microbiológicos nacionais, dois estariam desqualificados, dois foram compatíveis com a sua categoria e ou- tros dois atingiram padrões superiores aos neces. sários. Na metodologia quantitativa, todos apresentaram efeito germicida de pelo menos 5 em 15 segundos frente às cepas padrões. Surpreendentemente, um produto estava contaminado com Enterobacter $\mathrm{sp}$ na ordem de $10^{4}$ células por $\mathrm{ml}$ e esta cepa foi parcialmente resistente frente aos quatro outros produtos.

TIMENETSKY, J. [Evaluation of chemical disinfectants for household use]. Rev. Saúde públ., S. Paulo, 24: $47-50,1990$.

ABSTRACT: Five disinfectants for household use were advertised on television during 1988 and the first half of 1989. The products were tested by a qualitative (Use-Dilution with 10 carriers, a conventional and simplified, adapted method) and a qualitative, adapted method with a view to evaluating their antimicrobial activity. The active compounds of the products, according to their respective labels were: 1 - Parachlorophenol (0-Benzil) $0.1 \% ; 2$ - Eter $2.4 .4^{\prime}$ Chloro (III) 2 ' hydroxiphenylic $0.1 \% ; 3-$ $\mathrm{N}$ - alkyl dimethylbenzyl ammonium chlorides, $\mathrm{N}$ - alkyl dimethylethybenzyl ammonium $50 \%-1.6 \%$; 4 - Formaldehyde $37 \%$ ( $0.3 \%$ solution); 5 - No information. The microorganisms used were: Staphylococcus aureus ATCC 6538, Pseudomonas aeruginosa ATCC 15442 and Salmonella choleraesuis ATCC 10708. In the qualitative method the pseudomonas strain was recovered from disinfectants 1,2 , and 3 and the salmonella strain from disinfectants 2 and 3. All disinfectants showed germicidal effect $5.0(99.999 \%)$ of reduction) in 15 seconds against all strains. Disinfectant 3 was contamined with Enterobacter sp to the order of $10^{4}$ cells $/ \mathrm{ml}$. This contaminant was sensitive against disinfectants 1,4 and 5 , in the qualitative method and had a relative resistance to disinfectant 2 in the quantitative method.

KEYWORDS: Disinfectants. Microbiological evaluation.

\section{REFERÊNCIAS BIBLIOGRÁFICAS}

1.BLOOMFIELD, S.F. The use of disinfectants in home: a review. J. appl. Bacteriol., 45: 1-38, 1978.

2. CREMIEUX, A. \& FLEURETTE, J. Methods of testing disinfectants. In: Block, S.S., ed. Disinfection, sterilization and preservation. Philadelphia, Lea \& Febiger, 1983. p. $918-44$.

3. GONTIJO FILHO, P. P. \& ROMÃO, C. M. C. P. A. Testes microbiológicos e o registro de sanificantes, desinfetantes e antissépticos junto à Secretaria Nacional de Vigilância Sanitária. Rev. Microbiol., 17: 143-7, 1986.

4. INSTITUTO NACIONAL DE CONTROLE DE QUALIDADE EM SAUDE. Técnicas para o controle de qualidade; avaliação da atjvidade antibacteriana de saneantes domissanitários. Rio de Janeiro, Fundaçāo Oswaldo Cruz, 1985. (Manual Técnico $\mathrm{n}^{\circledR}$ 04/85).

5. MAURER, I. M. Chemical disinfectants: fiction and facto. In: Maurer, I. M. Hospital hygiene. 3rd ed. London, Edward Amold, 1985. p. 59-74.

6. MINISTÉRIO DA SAUDE. Anexo da Portaria $n^{2} 67$ de 21 de fevereiro de 1985. Diário Oficial da União, Brasília, 27 fev. 1985. Sec. 1/3181.

7. MINTSTÉRIO DA SAÚDE. Secretaria Nacional de Vigilância Sanitária. Desinfetantes domissanitários: comunicação sobre interdição cautelar de desinfetantes hospitalares. Brasília, 1986.

8. MINISTÉRIO DA SAÚDE. Secretaria Nacional de Vigilância Sanitária. Atualização sobre desirfetantes hospitalares. Rio de Janeiro, 1987. (Comunicado $n^{2} 4$, DISAD).
9. MNISTÉRIO DA SAÚDE. Secretaria Nacional de Vigilância Sanitária. Atualização sobre desinfetantes e esterilizantes hospitalares. Rio de Janeiro, 1987. (DISAD 10 de novembro de 1987).

10. MYERS, T. Failing the test: germicides or use dilution methodology? Amer. Soc. Microbiol. News, 54(1): 19 21,1988

11. PETROCCI, A. N. Surface-active agents: quatemary ammonium compounds. In: Block, S. S. Disinfection, sterilization and preservation. Philadelphia, Lea \& Febiger, 1983. p. $309-29$.

12. REYBROUCK, G. A theoretical approach of disinfectants testing. Zentralbl. Bakteriol. Parasitenkd. Infektionskr. Hyg. Abt. Orig. B., 160: 342-67, 1975.

13. REYBROUCK, G. The evaluation of the antimicrobial activity of disinfectants. In: Russel, A. D.; Hugo, W.B.; Ayliffe, G. A. J., eds. Principles and practice of disinfection, preservation and sterilization. London, Blackwell, 1982. p. 134-57.

14. SCOTT, E. \& BLOOMFIELD, S. F. A bacteriological investigation of the effectiveness of cleaning and disinfection procedures for toilet hygiene. J. appl. Bacteriol., 59: $291-7,1985$.

15. TIMENETSKY, J. \& ALTERTHUM, F. Determinação da atividade antimicrobiana de desinfetantes domésticos. Rev. Microbiol., 19(1): 46-51, 1988.

Recebido para publicação em 11/08/1989
Reapresentado em 11/12/1989
Aprovado para publicação em 15/12/1989 